\title{
Brachytherapy Boost to Carcinoma of the External Auditory Canal - Innovative Thinking - A Case Report
}

\author{
Harish Kumar ${ }^{1 *}$, Arunkumar $\mathbf{M N}^{2}$ and Selvaluxmy $\mathrm{G}^{3}$ \\ ${ }^{1}$ Assistant professor, Department of Radiation oncology, Cancer Institute (WIA), India \\ ${ }^{2}$ Assistant professor, Department of Radiation oncology, Cancer Institute (WIA), India \\ ${ }^{3}$ Professor/HOD, Department of Radiation oncology, Cancer Institute (WIA), India
}

Submission: April 04, 2019; Published: April 15, 2019

"Correspondence Author: Harish Kumar, Assistant professor, Department of Radiation oncology, Cancer Institute (WIA), Adyar, Chennai-20, India

\begin{abstract}
Squamous cell carcinoma of external auditory canal is a rare entity. It is usually managed with surgery followed by adjuvant radiation therapy in locally advanced disease, whereas in early disease single modality of treatment is preferred. In this article, we report a patient with squamous cell carcinoma of external auditory canal, treated with radical radiation - combination of external beam therapy followed by brachytherapy boost. HDR brachytherapy was executed using stethoscope ear piece and single $6 \mathrm{Fr}$ flexible brachytherapy catheter. Our idea is to highlight the technique and dosimetry of this procedure.
\end{abstract}

Keywords: External auditory canal; Brachytherapy

\section{Introduction}

Squamous cell carcinoma of the external auditory canal is quite rare. The reported incidence is 1 per 1000000 population. Traditionally surgery has been main modality of treatment for these tumours. Adjuvant radiotherapy has been advocated for patient with locally advanced disease. For early stage tumours, either primary surgery or radical radiotherapy has been the treatment of choice. Even though, surgery has been preferred by many oncologists for early stage tumours, there is high incidence of positive margin rates with surgery due to the complex anatomy of the structure and this will result in decreased survival rates. Radiotherapy has been proven to have equal efficacy rates in terms of tumour control and survival rates. Radiotherapy has been given by external beam radiotherapy and/or Brachytherapy. The combination of external beam radiotherapy and Brachytherapy has been found to have more beneficial for tumours in this location.

We treated one such patient with such a combination. Brachytherapy delivers high dose of radiation to tumour volume in a very precise and localised manner while sparing the nearby normal tissues. As a result, the radiation related side effects that are likely to occur with EBRT are significantly reduced. In addition, overall treatment time is shortened with maintenance of comparable local control rate with better cosmetic and functional outcome. In our case, brachytherapy was done using a stethoscope ear piece and a flexible polyethylene brachytherapy catheter. This ensured adequate immobilization and efficient treatment delivery which is being discussed in detail.

\section{Case Report}

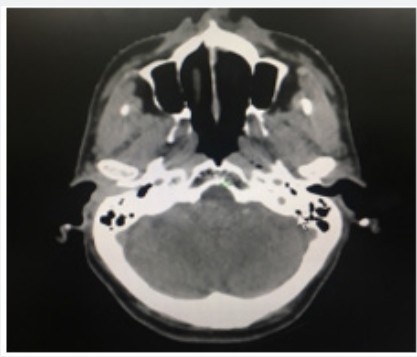

Figure 1a: CT PNS - Soft tissue lesion in Right EAC.

Our patient was an 82 yrs. old male, with hypothyroid and systemic hypertension as comorbid, on medications for the same for the past 12 years. He is an ex-smoker. He presented to us in Feb 2018 with complaints of Right ear impaired hearing associated with pain and discharge from right ear for 1-month duration [1]. Clinical examination revealed ulcerated lesion occupying right external auditory canal extending to middle ear [2,3]. Biopsy from lesion was suggestive of Squamous cell carcinoma, Grade II. CT PNS done (Figure 1a) - Right external auditory canal filled with soft tissue mass with no bony erosion. There were no nodes palpable clinically. Other routine blood investigations, 


\section{Cancer Therapy \& Oncology International Journal}

chest $\mathrm{X}$ ray were within normal limits. He was diagnosed to have Carcinoma of external auditory canal Stage T1 N0 M0. He was given the option of Radical surgery and radical radiotherapy. As patient was not willing of surgical procedure, he was planned for radical radiation after multidisciplinary board discussion.

\section{External Beam Radiation Therapy}

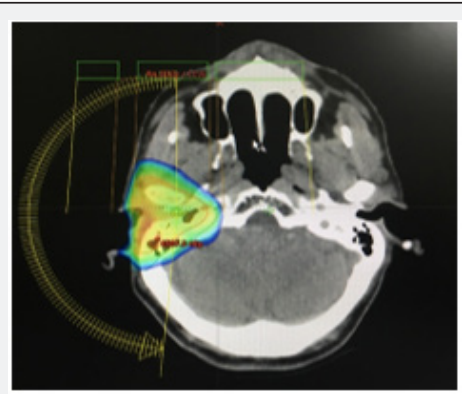

Figure 1b: EBRT Dose distribution - Rapid Arc therapy.

The patient initially underwent external beam radiotherapy (EBRT) up to a dose of 40 Gy in 20 fractions by Rapid Arc Radiotherapy technique. Patient was immobilized with thermoplastic mould and planning CT was done with $2 \mathrm{~mm}$ cuts. GTV was delineated and margin of $1.5 \mathrm{~cm}$ was given for CTV generation including tumour, petrosal bone, intra and infra parotideal nodes with ipsilateral retro auricular nodes. Due to the position of the tumour, rapid arc therapy resulted in a highly acceptable dose distribution (Figure 1b). He received 40 Gy in 20 fractions over a period of 26 days of $2 \mathrm{~Gy}$ per fraction. Patient tolerated treatment well with Gr I skin reaction.

\section{Brachytherapy}
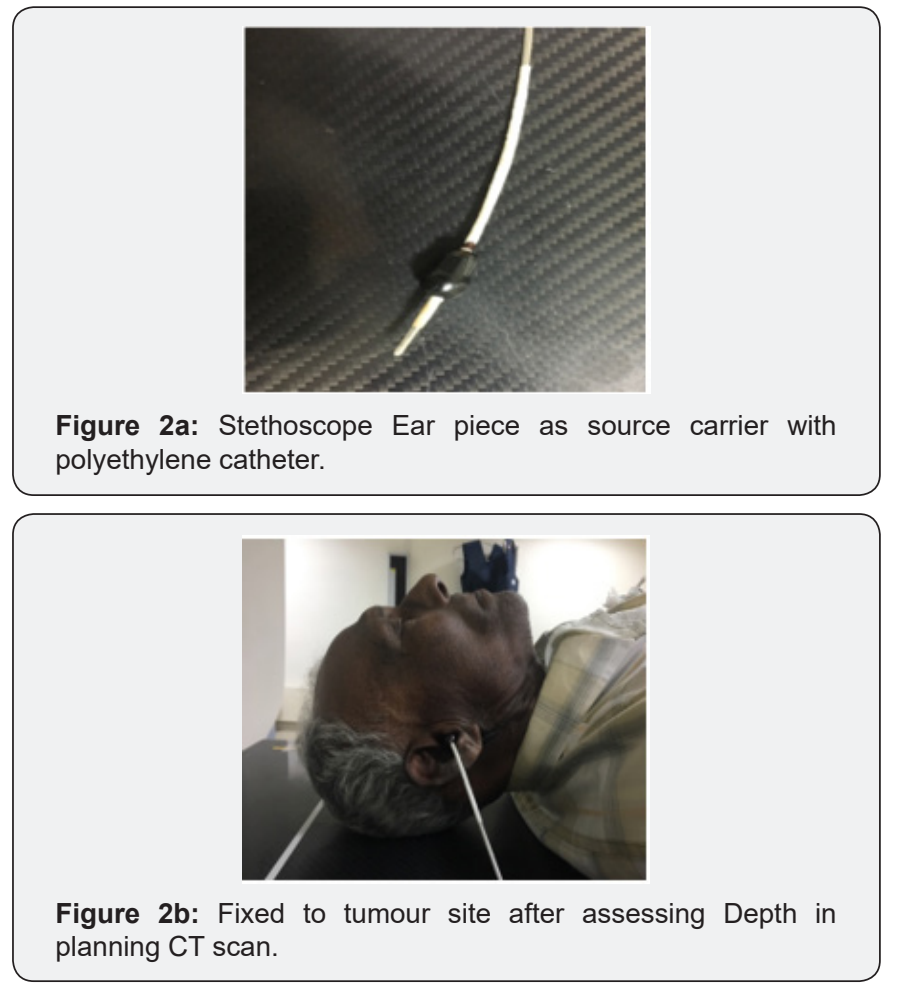

Immediate Clinical evaluation revealed satisfactory regression of lesion with minimal residual irregularity. It was decided to irradiate further with multiple fraction of brachytherapy, with an aim to deliver a dose of 20 Gy to the surface. (EQD2 - 66 Gy - 70 Gy Equivalent). After a gap of 1 week post External beam radiation, Customized applicator was prepared - A regular 6 Fr polyethylene catheter was used as a coaxial applicator. It was passed inside a stethoscope ear piece. The catheter and the ear piece were fixed to each other using micropore (Figures $2 \mathrm{a} \& 2 \mathrm{~b}$ ). The entire set up was fixed, after loading catheter filled with dummy seeds were fixed in position and the planning CT scan with $0.625 \mathrm{~mm}$ slice thickness was done with the same set up. Position of catheter was verified and adjusted according pre-RT tumour volume (Figure 3). The position of catheter is marked with permanent marker over micropore strip. PTV generated which included tumour volume with $0.75 \mathrm{~cm}$ margin.
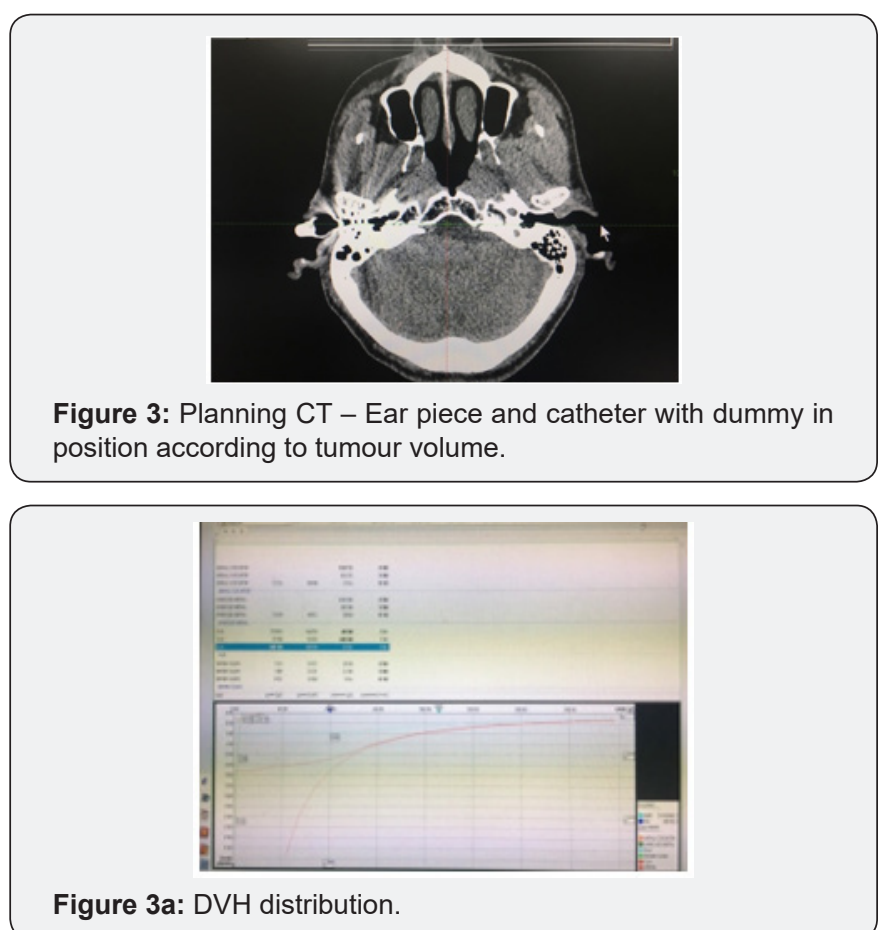

After necessary dose distribution optimization using different source position and dwell times, planned to deliver a total dose of 20 Gy in five fractions, two times a day over a period of three days to the relevant portion of the external auditory canal was generated with DVH verification (Figure 3a). The source transfer catheter was connected to the treatment microselectron unit through a coupling mechanism and the dose was delivered. The applicator remained fixed throughout the planning CT scan, treatment planning procedures and dose delivery, all of which lasted for about $1 \mathrm{hr}$ on day 1 . It was removed and carefully re-positioned in tumour cavity with help of external marker verification. A biological dose equivalent was calculated for 20 Gy (PD 150\%) and 15 Gy (100\% isodose covering PTV) and where 24 Gy and 16 Gy respectively (Figure 


\section{Cancer Therapy \& Oncology International Journal}

$3 b)$. It was thereby delivered with a combination of EBRT and brachytherapy. Patient tolerated the treatment well. No specific complaints or evidence of toxicity.

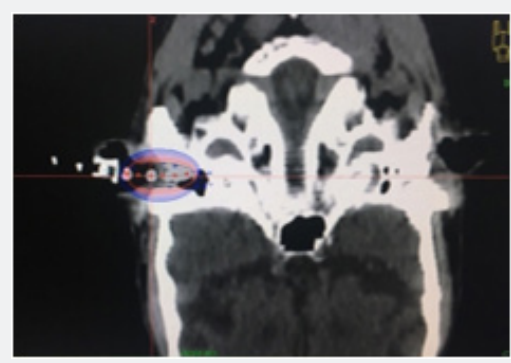

Figure 3b: BRT dose distribution with Isodose representation.

\section{Radiation Dose}

He received EBRT TD 40 Gy using Rapid Arc therapy from $27^{\text {th }}$ March to $20^{\text {th }}$ May 2018 followed by 20 Gy Ir 192 HDR brachytherapy (400cGy/\# - Twice daily for 3 days) - completed treatment on 02nd April 2018 - EQD2 of 66-70 Gy. On 1st follow up after 6 weeks - June 2018 - No evidence of disease clinically, no specific complaints. CT PNS done showed no evidence of gross residue.

\section{Discussion}

Squamous cell carcinoma constitutes $82 \%$ of the tumors involving the auditory canal, middle ear, and mastoid. They present with otorrhea and otalgia [4]. Chronic suppurative otitis media and previous irradiation are thought of as etiological factors. Early tumors are treated with radical radiation or surgery. Postoperative radiotherapy has been found to be beneficial in reducing the local recurrence in these tumours, more so for those with questionable margins, nodal disease or T2-3 diseases. In our case, the patient had an early stage disease but was reluctant to undergo a surgery. It was decided to treat him aggressively with radical radiation.

The literature has suggested that doses of over 60 - 70 Gy are related to better local recurrence and disease-free survival than lower doses. Brachytherapy was involved due to its efficacy in dose delivery with a rapid fall off, sparing the adjacent bone. The un-uniform contour and the eloquent location of the tumour were challenges for the dose delivery with external beam therapy. This was overcome using high dose rate brachytherapy. Making of source carrier with ear piece of stethoscope is easy and does not require high investment or invasive procedure. The use of the stethoscope ear piece enabled proper immobilization of the catheter and hence dose delivery was optimal. Patient movement was not a concern in brachytherapy.

We could optimize the dose distribution such that the medial portion of the external auditory canal near the eardrum, where the tumour was found could be irradiated efficiently [5]. The use of Ir 192 after loading brachytherapy in combination with EBRT has been said to provide less side effects and better cosmesis.

\section{Conclusion}

Squamous cell carcinomas of the external auditory canal are, usually, diagnosed late due to the nonspecific presentation. The combination of external beam therapy and Ir 192 HDR brachytherapy would be the optimal treatment for early disease [6]. Brachytherapy could be thought of in combination with EBRT, wherever possible. The high-risk areas thereby receive high doses, and this leads to better tumour control. However, we need long term follow up to account on long term morbidity like canal stenosis, otitis media with effusion and Osteoradionecrosis. Also, more experience with additional cases is necessary to establish this treatment protocol.

\section{References}

1. Lederman M (1965) Malignant tumours of the ear. J Laryngol Otol 79: 85-119.

2. Lim LH, Goh YH, Chan YM, Chong VF, Low WK (2000) Malignancy of the temporal bone and external auditory canal. Otolaryngol Head Neck Surg 122(6): 882-886.

3. Kuhel WI, Hume CR, Selesnick SH (1996) Cancer of the external auditory canal and temporal bone. Otolaryngol Clin North Am 29: 827-852.

4. Ogawa K, Nakamura K, Hatano K, Uno T, Fuwa N, et al. (2007) Treatment and prognosis of squamous cell carcinoma of the external auditory canal and middle ear: A multi-institutional retrospective review of 87 patients. International Journal of Radiation Oncology Biology Physics 68: 1326-1334.

5. Shimatani Y, Kodani K, Mishima K, Ametani M, Ogawa T, et al. (2002) Evaluation of the results of radiotherapy for carcinoma involving the external auditory canal or middle ear. Nihon Igaku Hoshasen Gakkai Zasshi 62: 739-743.

6. Budrukkar A, Bahl G, Bhalavat R, Laskar SG, Agarwal JP, et al. (2009) High-dose-rate brachytherapy boost for carcinoma of external auditory canal. Brachytherapy 8: 392-395. 
This work is licensed under Creative Commons Attribution 4.0 License DOI: 10.19080/CTOIJ.2019.13.555863
Your next submission with Juniper Publishers will reach you the below assets

- Quality Editorial service

- Swift Peer Review

- Reprints availability

- E-prints Service

- Manuscript Podcast for convenient understanding

- Global attainment for your research

- Manuscript accessibility in different formats ( Pdf, E-pub, Full Text, Audio)

- Unceasing customer service

Track the below URL for one-step submission https://juniperpublishers.com/online-submission.php 